\title{
An audit of the labour epidural analgesia service at a regional hospital in Gauteng Province, South Africa
}

\author{
T Leonard, ${ }^{1} \mathrm{MB}$ BCh, DA (SA), FCA (SA), MMed (Anaes); H Perrie, ${ }^{1}$ MSc; J Scribante,${ }^{1} \mathrm{PhD}$; \\ S Chetty, ${ }^{1,2}$ MB ChB, DCH (SA), DA (SA), FCA (SA), Cert Crit Care (SA), PhD
}

${ }^{1}$ Department of Anaesthesiology, School of Clinical Medicine, Faculty of Health Sciences, University of the Witwatersrand, Johannesburg, South Africa

${ }^{2}$ Department of Anaesthesiology and Critical Care, Faculty of Medicine and Health Sciences, Stellenbosch University, Cape Town, South Africa

Corresponding author: T Leonard (tristanleonard@hotmail.com)

\begin{abstract}
Background. Neuraxial analgesia in the form of a labour epidural has been shown to be the most effective analgesic strategy for the labouring mother. In developed countries, data are readily available as to the number of women receiving labour epidural analgesia, as well as the complication rates of labour epidurals. However, data for South Africa (SA) on labour epidural analgesia services are limited, and there were no published data for Rahima Moosa Mother and Child Hospital (RMMCH), Johannesburg, SA.

Objective. To describe the labour epidural analgesia service at RMMCH over the period of 1 year.

Methods. A retrospective audit using consecutive convenience sampling was done reviewing all epidural records at $\mathrm{RMMCH}$ from 1 January to 31 December 2014.

Results. During the study period, labour epidural analgesia was administered for 187 (1.6\%) of 11853 deliveries. Epidural records were collected for all administered labour epidurals. The most common indications documented were labour analgesia (41.7\%) and primigravida (28.9\%). Labour epidurals were not administered for specific medical conditions. The incidence of complications was $22.6 \%$, and these were minor and self-limiting. Hypotension was the most common complication (12.3\%). Patient satisfaction with labour epidural analgesia, where documented, was high (98.4\%).

Conclusion. This audit revealed a low incidence of labour epidural analgesia at RMMCH during the study period. The incidence of complications was in keeping with that seen in developed countries. Poor documentation was noted to be a problem.
\end{abstract}

S Afr J Obstet Gynaecol 2018;24(2):52-56. DOI:10.7196/SAJOG.2018.v24i2.1314

All humans are faced with episodes of pain in their lifetime - the experience can range from mild and self-limiting to severe and debilitating pain. The pain that a woman experiences during childbirth can arguably be described as the most severe pain that she will experience in her life. ${ }^{[1,2]}$ This pain has been described as being worse than cancer pain or having a digit amputated without anaesthesia. ${ }^{[3]}$

Not only is this pain distressing for the mother, but it can also have detrimental effects on maternal and fetal wellbeing. Activation of the sympathetic nervous system due to pain leads to large rises in circulating adrenaline and noradrenaline levels. ${ }^{[4]}$ These increases in catecholamine levels have significant effects on maternal physiology, especially for mothers with cardiac conditions such as valvular heart disease, cardiomyopathy and ischaemic heart disease. These include an increase in heart rate and cardiac output, which leads to increases in myocardial oxygen demand, placing the myocardium at risk for ischaemia, as well as causing a decrease in placental blood flow. ${ }^{[5]}$ This decrease in placental blood flow can cause fetal hypoxia and acidosis. Labour pain is also a potent stimulant of respiratory drive, leading to hyperventilation, with a subsequent increase in minute ventilation and maternal respiratory alkalosis; this causes a left shift of the oxygen haemoglobin dissociation curve, and impairs oxygen delivery to the fetus. ${ }^{[6]}$

Untreated labour pain can also have detrimental psychological effects on mothers. In the 1990s, a series of case studies conducted by Ballard et al..$^{[7]}$ and a cross-sectional study by Wijma et al. ${ }^{[8]}$ showed that traumatic childbirth can be a risk factor for the development of post-traumatic stress disorder, with subsequent long-term effects on maternal mental health and maternalfetal bonding. Furthermore, in 2008, Eisenach et al. ${ }^{[9]}$ enrolled 1288 women in a survey to determine the impact of pain during childbirth on subsequent mental health. It was found that severe peripartum pain was independently associated with postpartum depression, and that women who experienced severe peripartum pain had a threefold increased risk of post-traumatic stress disorder. Owing to the well-described adverse effects of pain in labour, there is a worldwide effort toward ensuring that mothers are offered adequate analgesia in the peripartum period. Studies and reviews have been conducted over a number of years, and there is consensus that lumbar epidural analgesia is the gold standard for labour analgesia, by providing the most effective, reliable and flexible method of pain relief during labour. ${ }^{[1,10,11]}$

According to the American Society of Anesthesiologists and the American College of Obstetrics and Gynecology, in the absence of a medical contraindication, maternal request is a sufficient medical indication for pain relief during labour'.[11] This is reflected in the number of women receiving epidural analgesia in developed countries, with rates in the $\mathrm{UK}^{[12]}$ and in large hospitals in the USA ${ }^{[13]}$ being reported as $49.3 \%$ and $61 \%$, respectively.

Data regarding the proportion of women receiving labour epidural analgesia in developing countries are limited, but it is assumed to be much lower than in developed countries. Hu et al. ${ }^{[14]}$ 
reported a labour epidural rate of less than 1\% in China in 2007. This was increased to $50 \%$ in some hospitals following the No Pain Labor \& Delivery initiative. In India, the epidural rate during labour is only $11 \% \cdot{ }^{[15]}$

Data for South Africa (SA) are also limited. A recent audit at a tertiary public hospital in the Western Cape revealed that only 2.2\% of labouring mothers received labour epidural analgesia, and that epidural placement was done for a medical indication, upon request from an obstetrician, and not on patient request. ${ }^{[16]} \mathrm{A}$ follow-up study in 2014, after the establishment of a dedicated epidural service at the same hospital, revealed that the epidural rate had increased to $5.2 \%$. $^{[17]}$

Epidurals are considered safe, but when serious complications occur, they can be fatal or lead to permanent harm. ${ }^{[6]}$ An audit by the Royal College of Anaesthetists in $2009^{[18]}$ found the incidence of permanent harm after epidural to be 0.6 per 100000 cases (95\% confidence interval 0 - 3.4), and a survey in France found an incidence of serious events related to obstetric epidural to be less than 5 in $10000{ }^{[19]}$ Data on complications with respect to obstetric epidural analgesia are again limited in SA, but an audit in the Western Cape Province showed a serious complication rate of $0.7 \% .^{[16]}$

There are no data on the labour epidural analgesia service at Rahima Moosa Mother and Child Hospital (RMMCH), and the aim of this study was to describe the labour epidural analgesia service at $\mathrm{RMMCH}$ over a period of 1 year.

\section{Methods}

A retrospective, contextual, descriptive research design was followed. Approval to conduct the study was obtained from the University of the Witwatersrand Human Research Ethics Committee (Medical), (ref. no. M150112), and other relevant authorities.

The standard, existing labour epidural service at RMMCH during 2014 was a Monday-to-Friday office-hour service. An anaesthetist (medical officer or registrar) was on call for the labour ward to administer epidurals, in consultation with the obstetric staff. The anaesthetist was also able to identify appropriate patients during the day and offer an epidural, after discussion with the responsible nursing sister. Informed written consent for the epidural was obtained prior to insertion, and the event recorded manually on a single-page, pre-printed labour epidural chart. Once the patient had delivered her baby and the anaesthetist had removed the epidural, the epidural records were placed in a file on the epidural trolley. These completed records were collected by the consultant responsible for overseeing the epidural service, and were stored in a secure site in the anaesthetic department.

An audit of the labour epidural analgesia service for the period 1 January to 31 December 2014 was conducted using consecutive convenience sampling. The labour ward admission book was used to determine the number of deliveries, including caesarean sections (CSs), during the study period.

Each epidural record was assigned a study number, which was recorded together with the patient's hospital number on a separate Word (Microsoft, USA) document. This would allow specific records to be identified if necessary. During data collection and analysis, only study numbers were used, to ensure anonymity.

Data were collected using standard data collection sheets adapted from an audit on the epidural analgesia service at Tygerberg Hospital. ${ }^{[16]}$ Permission to use this instrument was obtained from the corresponding author. The data collected are summarised in Table 1.
All captured data were recorded and analysed in an Excel (Microsoft, USA) spreadsheet. Descriptive statistics were used. Categorical data were summarised using frequencies and percentages. Continuous variables that were normally distributed were summarised using means and standard deviations (SDs) and variables that were not normally distributed were summarised using medians and interquartile ranges (IQRs).

\section{Results}

The results of this study are summarised in Table 2. During the study period, 11853 patients were managed for labour and delivery

\section{Table 1. Data collected at RMMCH}

\section{Variable}

General demographics (total deliveries, caesarean sections, epidural analgesia records retrieved and records lost to follow-up)

Patient demographics

Primary indication for labour epidural

Professional designation of the doctor inserting the epidural

Epidural technique

Complications

Patient satisfaction

Time to follow-up after removal of the epidural catheter

RMMCH = Rahima Moosa Mother and Child Hospital.

Table 2. Summary of results obtained from RMMCH $(N=11853)$

\begin{tabular}{|c|c|}
\hline Variable & $n(\%)$ \\
\hline \multicolumn{2}{|l|}{ Demographics } \\
\hline Total deliveries & 11853 \\
\hline Total caesarean sections & $3883(32.8)$ \\
\hline Total epidurals performed & $187(100)$ \\
\hline Epidural records retrieved & 187 \\
\hline \multicolumn{2}{|l|}{ Indication } \\
\hline Labour analgesia & $78(41.7)$ \\
\hline Primigravida & $54(28.9)$ \\
\hline Augmentation of labour & $1(0.5)$ \\
\hline Not recorded & $54(28.9)$ \\
\hline \multicolumn{2}{|l|}{ Professional designation } \\
\hline Registrar & $104(55.6)$ \\
\hline Medical officer & $70(37.4)$ \\
\hline Consultant & $1(0.5)$ \\
\hline Not recorded & $12(6.4)$ \\
\hline Epidural technique not recorded & $187(100)$ \\
\hline \multicolumn{2}{|l|}{ Complications } \\
\hline No complication & $120(64.2)$ \\
\hline Hypotension & $23(12.3)$ \\
\hline Incomplete analgesia & $6(3.2)$ \\
\hline Back pain & $5(2.7)$ \\
\hline Pyrexia & $1(0.5)$ \\
\hline Not recorded & $32(17.1)$ \\
\hline \multicolumn{2}{|l|}{ Time to follow-up } \\
\hline Within 24 hours & $124(66.3)$ \\
\hline Not recorded & $63(33.7)$ \\
\hline \multicolumn{2}{|l|}{ Patient satisfaction } \\
\hline Very happy & $64(34.2)$ \\
\hline Happy & $58(31.0)$ \\
\hline Not happy & $2(1.1)$ \\
\hline Not recorded & $63(33.7)$ \\
\hline
\end{tabular}


at RMMCH. Normal vertex deliveries and CSs accounted for $7970(67.2 \%)$ and $3883(32.8 \%)$ of deliveries, respectively. A total of $187(1.6 \%)$ epidurals were administered in the labour ward during the year. Labour epidural records were collected for $100 \%$ of labour epidurals administered.

The mean (SD) age of patients who received labour epidural analgesia was $26(5.4)$ years. There were $80(42.8 \%)$ primigravida, $50(26.7 \%)$ para 2 and $3(1.6 \%)$ patients of greater parity. The parity of $34(18.2 \%)$ patients was not recorded.

The most common recorded indications for epidural analgesia were labour analgesia in $78(41.7 \%)$ patients and primigravida in $54(28.9 \%)$ patients. One (0.5\%) patient had augmentation of labour as an indication. There was no indication recorded for $54(28.9 \%)$ of the patients. Registrars and medical officers administered 174 (93.0\%) epidurals, with 12 (6.4\%) records having no identifying name recorded. One $(0.5 \%)$ epidural was administered by a consultant. No details with regard to the epidural technique used (approach and loss of resistance) were recorded for any patients.

The majority $(120(64.2 \%))$ of patients experienced no complications following labour epidural, with data not recorded in 32 (17.1\%) cases. There were no major complications. Minor complications occurred in 35 (18.7\%) patients. Follow-up was done within 24 hours of removal of the epidural catheter in 124 (66.3\%) patients, and there was no documentation of follow-up for the remaining 63 (33.7\%) patients.

Patient satisfaction with their epidural analgesia was recorded in $124(66.3 \%)$ patients, and was rated as very happy and happy in $122(65.2 \%)$ patients, representing $98.4 \%$ of patients where documentation was complete. There were $2(1.1 \%)$ patients who were not happy with the labour epidural analgesia.

\section{Discussion}

The epidural rate of $1.6 \%$ at $\mathrm{RMMCH}$ was low compared with rates in developed countries. In the UK, the rate of labour epidural analgesia has ranged from $24 \%$ to $49.3 \%$ over the last decade, ${ }^{[12,20]}$ with rates of $58.3 \%$ and $61 \%$ in $\mathrm{Canada}^{[21]}$ and the USA, ${ }^{[13]}$ respectively. Data on epidurals in developing countries are limited, but there is a general low provision of labour analgesia and labour epidurals. ${ }^{[22-24]}$ Data from India and China reveal rates of labour epidural analgesia of $11 \%$ and $1 \%$, respectively, with the rate in China increasing to $50 \%$ following a major intervention over 10 years. ${ }^{[14,15]}$ An audit at Tygerberg Hospital, Cape Town, SA, showed an epidural rate of $2.2 \%$, which is in keeping with the findings of this audit. ${ }^{[16]}$ This increased to $5.2 \%$ after the establishment of a dedicated epidural service. $^{[17]}$

The reasons for the low epidural rate in our study are multifactorial and include a limited number of anaesthetists available to provide labour epidurals. During the study period, there was a single anaesthetist on call for labour epidurals from Monday to Friday during the daytime ( $07 \mathrm{~h} 00$ to $16 \mathrm{~h} 00$ ) only. There was no afterhours service. There is also an anecdotal perception among nursing staff that labour epidurals lead to higher CS rates, even though this is not the case based on the literature ${ }^{[25]}$ and hence there is resistance among nurses to widespread insertion of labour epidurals in the labour ward.

At Tygerberg Hospital, the indications for epidural analgesia were primarily for medical conditions that needed amelioration of the neuroendocrine stress response during labour. ${ }^{[16]}$ Our audit has revealed that the primary indications for labour epidural were for labour analgesia or for primigravidas, who often experience severe pain in labour, which is more in line with the American Society of Anesthesiologists and American College of Obstetrics and Gynecology statement that in the absence of a medical contraindication, maternal request is a sufficient medical indication for pain relief during labour. ${ }^{[11]}$ The epidurals done at $\mathrm{RMMCH}$ during the study period were primarily for pain relief, albeit not at maternal request. It is also worth noting that at the time of the audit, $\mathrm{RMMCH}$ was a regional hospital as compared to Tygerberg Hospital, a tertiary hospital, and as such RMMCH does not manage cardiac patients or the morbidly obese, which could explain the differences in indications for labour epidurals.

The epidural technique used (approach and loss of resistance) was not recorded on any of the epidural records. There is no place on the current epidural record used at RMMCH to record the epidural technique, which would prompt the anaesthetist to complete this section. An unpublished MMed study by Jacobs-Martin et al.$^{[16]}$ in SA on the characteristics of an ideal epidural record has shown that this is essential data that should be recorded for all epidurals done.

Major complications, defined as death, paraplegia, cardiac arrest, respiratory failure, seizures and meningitis from labour epidurals are rare. ${ }^{[19]}$ Two large audits in France and the UK revealed serious major complications of 5 in 29732 and 0.6 in 100000 cases, respectively. ${ }^{[18,19]}$ There were no major complications during the study period at RMMCH. Maternal fever is a potentially serious complication of labour epidural analgesia, and requires more investigation. The mechanism of maternal pyrexia is unknown, but is thought to involve thermoregulatory and inflammatory mechanisms. An incidence of $1-46 \%$ was shown in a review by Segal in 2010. ${ }^{[26]}$ There was one patient who experienced pyrexia in this study, and this was mild and resolved without treatment within 24 hours after the epidural.

Minor complications occurred in $18.7 \%$ of patients. These were all self-limiting. Hypotension, as indicated by the anaesthestist performing the epidural, reflecting a drop in systolic blood pressure of more than $20 \%$ from baseline, occurred in $12.3 \%$ of patients. The other complications were incomplete analgesia (3.2\%) and back pain $(2.7 \%)$. This is in keeping with the findings on complications of labour epidural analgesia by Paech et al. ${ }^{[27]}$ which in a prospective study of 10995 labour epidurals in Australia found an incidence of hypotension of $4.9 \%$ and of failed (incomplete) analgesia of $1.7 \%$. Singh et al. ${ }^{[28]}$ in the USA showed a failed (incomplete) analgesia incidence of $0.65 \%$. The incidence of hypotension in our study is similar to that found by Jacobs-Martin et al. ${ }^{[16]}$ at Tygerberg Hospital, who reported an incidence of $13.4 \%$. However, these authors reported a higher incidence of back pain $(7.4 \%)$ in their study, compared with $2.7 \%$ in our study. The five patients who reported back pain in this audit all experienced the pain at the time of epidural catheter insertion. There was no incidence of back pain reported at the 24-hour follow-up in any patients. Evidence with respect to lower back pain from epidural analgesia is conflicting, with MacArthur et al. ${ }^{[29]}$ reporting an incidence of lower back pain on day one following labour epidural analgesia of 56\%. However, Howell et al..$^{[30]}$ in 2001 concluded that 'this study provided no evidence to support the suggestion of a direct association between the use of epidural anaesthesia in labour and the incidence of long term backache.' The lack of lower back pain in our audit could be due to the lack of adequate follow-up, as well as differences in patient demographics from those in Europe and the USA. 
There was no incidence of unintentional dural puncture and postdural puncture headache in our study. The Australian study by Paech et al. ${ }^{[27]}$ showed an incidence of unintentional dural puncture of $0.6 \%$. In the study by Singh et al. ${ }^{[28]}$ in the USA, the incidences of unintentional dural puncture and postdural puncture headache were $0.73 \%$ and $0.49 \%$, respectively, while at Tygerberg Hospital they were $4 \%$ and $3.4 \%$, respectively. ${ }^{[16]}$ The lack of these complications at RMMCH could be due to the low number of epidurals administered, and as such, the study is not powered to detect them, but it could also be a result of poor documentation. The section for complication on the epidural record was not completed in $18.9 \%$ of cases, and it cannot be assumed that these patients did not experience any complication following labour epidural analgesia.

It is concerning that there was no documentation of follow-up after removal of the labour epidural catheter in $33.7 \%$ of cases, with the remaining $66.3 \%$ all being followed up within 24 hours. RMMCH is a very busy hospital with thousands of deliveries each year, and as such, the majority of patients are discharged 6 hours after normal vaginal delivery. This could explain some of the difficulty with regard to patient follow-up, but is also an example of the failure of adequate documentation of cases, as well the failure to apply hospital protocols.

A high level of patient satisfaction with epidural analgesia has been consistently demonstrated. ${ }^{[30-32]}$ Satisfaction in this audit was measured as 'very happy', 'happy' or 'not happy'. The majority of patients reported being very happy $(34.2 \%)$ or happy $(31.0 \%)$, with only two patients $(1.1 \%)$ reporting being not happy. Both of these patients had experienced incomplete analgesia. When considering the lack of documentation of patient satisfaction in $63(33.7 \%)$ the patients, reporting being happy and very happy reflect $98.4 \%$ of those where documentation was complete. These findings are in keeping with research by Howell et al. ${ }^{[30]}$ and Sharma et al. ${ }^{[32]}$ who reported high levels of patient satisfaction with labour epidural analgesia of $85 \%$ and $95 \%$, respectively.

There was a consistent problem with lack of adequately completed epidural records at RMMCH. For each variable that was assessed, there were data that were not recorded. This poor documentation reflects inadequate application of protocols, and could have medicolegal consequences if there were to be any future litigation regarding a labour epidural that was inserted at $\mathrm{RMMCH}$.

A 24-hour labour epidural service has been introduced at RMMCH subsequent to this study. There has also been increased education of nursing staff, and efforts to enhance awareness regarding labour epidurals in the labour ward, and it would be prudent to investigate the change that this has had on the epidural rate. This is an avenue for future research.

A limitation of this study would be that in determining the percentage of patients receiving labour epidural analgesia, it would be ideal to exclude patients who had elective CS deliveries, as these patients would never have been in labour nor been candidates for labour epidural analgesia. Information on how many CSs were elective during the study period is not available from $\mathrm{RMMCH}$.

\section{Conclusion}

This audit investigated the labour epidural analgesia service at $\mathrm{RMMCH}$. There was a low incidence of labour epidural analgesia of $1.6 \%$. This is much lower than international standards. There were no major complications during the study period, and the incidence of minor complications was in keeping with complication rates identified in large studies in developed countries, as well as one study in SA. Furthermore, a failure of adequate documentation was identified. This is an area for future education and changes in practice at $\mathrm{RMMCH}$.

The introduction of a 24-hour epidural service at $\mathrm{RMMCH}$ provides a research opportunity to assess the impact of this intervention, and the new incidence of labour epidural analgesia.

Acknowledgements. TL would like to acknowledge the help of his supervisors on the project, as well as the support of A Murphy.

Author contributions. TL collected and analysed the data and completed the research report and article. HP and JS assisted with the research methodology and as academic supervisors. SC was the clinical supervisor.

Funding. All funding was provided by the Department of Anaesthesiology, School of Clinical Medicine, Faculty of Health Sciences, University of the Witwatersrand.

\section{Conflicts of interest. None.}

1. Wong C. Advances in labor analgesia. Int J Womens Health 2009;1(1):139-154. https://doi. org/10.2147/ijwh.s4553

2. Melzack R. The myth of painless childbirth (The John J. Bonica Lecture). Pain 1984;19(4):321-337. https://doi.org/10.1016/0304-3959(84)90079-4

3. Niven C, Gijsbers K. A study of labour pain using the McGill pain questionnaire. Soc Sci Med 1984;19(12):1347-1351. https://doi.org/10.1016/0277-9536(84)90023-6

4. Lederman R, McCann D, Work B, Huber M. Endogenous plasma epinephrine and norepinephrine in last-trimester pregnancy and labor. Am J Obstet Gynaecol 1977;129(1):5-8. https://doi. org/10.1016/0002-9378(77)90809-2

5. Alran S, Sibony O, Oury J, Luton D, Blot P. Differences in management and results in termdelivery in nine European referral hospitals: Descriptive study. Eur J Obstet Gynecol Reprod Biol 2002;103(1):4-13. https://doi.org/10.1016/s0301-2115(02)00028-3

6. Butterworth J, Mackey D, Wasnick J. Morgan \& Mikhail's Clinical Anesthesiology, 5th ed. New York: McGraw-Hill Companies, 2013.

7. Ballard C, Stanley A, Brockington IF. Post-traumatic stress disorder (PTSD) after childbirth. Br J Psychiatry 1995;166(4):525-528. https://doi.org/10.1192/bjp.166.4.525

8. Wijma K, Söderquist J, Wijma B. Post-traumatic stress disorder after childbirth: A cross-sectional study. J Anxiety Disord 1997;11(6):587-597. https://doi.org/10.1016/s0887-6185(97)00041-8

9. Eisenach J, Pan P, Smiley R, Lavand'homme P, Landau R, Houle T. Severity of acute pain after childbirth, but not type of delivery, predicts persistent pain and postpartum depression. Pain 2008;140(1):87-94. https://doi.org/10.1016/j.pain.2008.07.011

10. Ranasinghe J, Birnbach D. Progress in analgesia for labor: Focus on neuraxial blocks. Int J Womens Health 2009;1(1):31-43. https://doi.org/10.2147/ijwh.s4552

11. American Society of Anesthesiologists (ASA) and the American College of Obstetricians and Gynecologists (ACOG). Statement on Pain Relief During Labor 2010. https://www.asahq.org/ForMembers/ /media/For Members/documents/Standards Guidelines Stmts/Statement Pain Relief Laborashx (accessed 16 October 2014).

12. Hospital Episode Statistics Analysis Health and Social Care Information Centre. NHS Maternity Statistics. London: National Health Service, 2013.

13. Bucklin B, Hawkins J, Anderson J, Ullrich F. Obstetric anesthesia workforce survey. Anesthesiology 2005;103(3):645-653. https://doi.org/10.1097/00000542-200509000-00030

14. Hu Y, Flood P, Li Y, et al. No pain labor and delivery: A global health initiative's impact on clinical outcomes in China. Anesth Analg 2016;122(6):1931-1938. https://doi.org/10.1213/ ANE.0000000000001328

15. Pandya S. Labour analgesia: Recent advances. Indian J Anaesth 2010;54(5):400-408. https://doi. org/10.4103\%2F0019-5049.71033

16. Jacobs-Martin G, Burke J, Levin A, Coetzee A. Labour epidural analgesia audit in a tertiary state hospital in South Africa. S Afr J Anaesth Analg 2014;20(4):174-178. https://doi.org/10.1080/22201 181.2015.959344

17. Van Zyl S, Burke J. Increasing the labour epidural rate in a state hospital in South Africa: Challenges and opportunities. S Afr J Anaesth Analg 2017;23(6):156-161. https://doi.org/10.1080/22201181.2 017.1401773

18. Cook T, Counsell D, Wildsmith J. Major complications of central neuraxial block: Report on the Third National Audit Project of the Royal College of Anaesthetists. Br J Anaesth 2009;102(2):179190. https://doi.org/10.1093/bja/aen360

19. Auroy Y, Benhamou D, Bargues L, et al. Major complications of regional anesthesia in France. Anesthesiology 2002;97(5):1274-1280. https://doi.org/10.1097/00000542-200211000-00034

20. Grond S, Meuser T, Stute P, Göhring U. Epidural analgesia for labour pain: A review of availability current practices and influence on labour. Acute Pain 2000;3(1):1-13. https://doi.org/10.1016 S1366-0071(00)80007-8

21. Canadian Institute for Health Information. Inpatient Hospitilizations, Surgeries and Childbirth Indicators 2012 - 2013.Toronto: Government of Canada, 2013.

22. Qian X, Smith H, Zhou L, Liang J, Garner P. Evidence-based obstetrics in four hospitals in China: An observational study to explore clinical practice, women's preferences and provider's views. BMC An observational study to explore clinical practice, women's preferences and
Pregnancy Childbirth 2001;1(1):1-7. https://doi.org/10.1186/1471-2393-1-1

23. Obuna J, Umeora O. Perception of labor pain and utilisation of obstetric analgesia by Igbo women of Southeast Nigeria. J Obstet Anaesth Crit Care 2014;4(1):18-22. https://doi.org/10.4103/22494472.132815

24. Ogboli-Nwasor E, Adaji S, Bature S, Shittu O. Pain relief in labor: A survey of awareness, attitude, and practices of health care providers in Zaria, Nigeria. J Pain Res 2001;4(1):227-232. https://doi. org/10.2147\%2FJPR.S21085

25. Grant E, Tao W, Craig M, McIntire D, Leveno K. Neuraxial analgesia effects on labour progression: Facts, fallacies, uncertainties and the future. Br J Obstet Gynaecol 2014;122(3):288-293. https://doi. org/10.1111/1471-0528.12966

26. Segal S. Labor epidural analgesia and maternal fever. Anesth Analg 2010;111(6):1467-1475. https:// doi.org/10.1213/ANE.0b013e3181f713d4 


\section{RESEARCH}

27. Paech M, Godkin R, Webster S. Complications of obstetric epidural analgesia and anaesthesia: A prospective analysis of 10995 cases. Int J Obstet Anesth 1998;7(1):5-11. https://doi.org/10.1016/ s0959-289x(98)80021-6

28. Singh S, Chaudry S, Phelps A, Vallejo M. A 5-year audit of accidental dural punctures, postdural puncture headaches, and failed regional anesthetics at a tertiary-care medical center. Scientific World J 2009;9(1):715-722. https://doi.org/10.1100/tsw.2009.94

29. MacArthur A, MacArthur C, Weeks C. Epidural anaesthesia and low back pain after delivery: A prospective cohort study. Br Med J 1995;311(7016):1336-1339. https://doi.org/10.1136/ bmj. 311.7016 .1336

30. Howell C, Kidd C, Roberts W, et al. A randomised controlled trial of epidural compared with non-epidural analgesia in labour. Br J Obstet Gynaecol 2001;108(1):27-33. https://doi org/10.1111/ j.1471-0528.2001.00012.x
31. Dickinson J, Paech M, McDonald S, Evans S. Maternal satisfaction with childbirth and intrapartum analgesia in nulliparous labor. Aust N Z J Obstet Gynaecol 2003;43(6):463-468. https://doi. org/10.1046/j.0004-8666.2003.00152.x

32. Sharma S, McIntire D, Wiley J, Leveno K. Labor analgesia and caesarean delivery: An individual patient meta-analysis of nulliparous women. Anaesthesiology 2004;100(1):142-148. https://doi org/10.1097/00000542-200401000-00023

Accepted 12 September 2018 